\title{
EDIN
}

Energy Development in Island Nations

U.S. Virgin Islands

\section{USVI Energy Road Map Charting the Course to a Clean Energy Future}

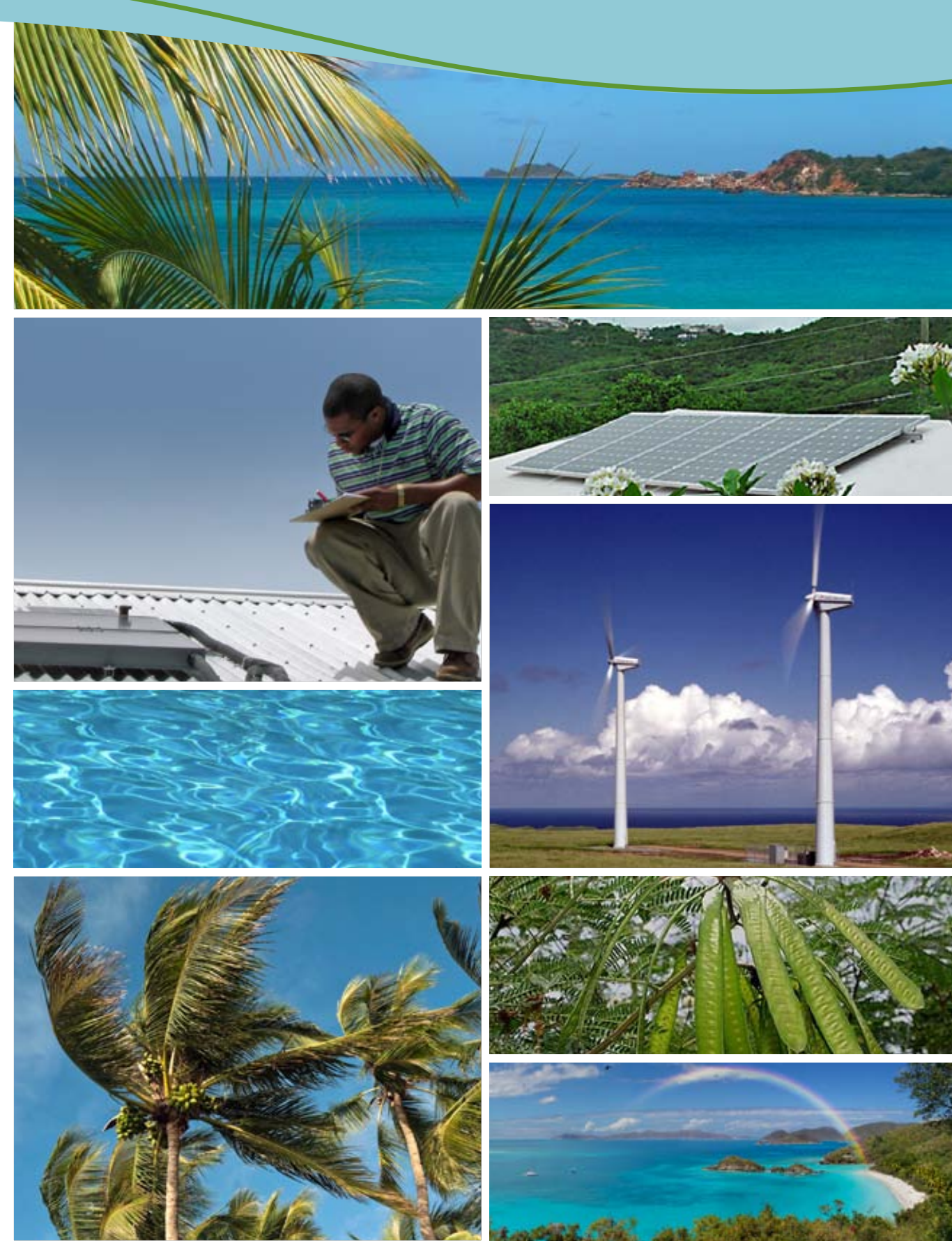




\section{The Urgent Need}

for Change

Energy transformation. It's an enormous undertaking.

One that has been discussed for decades. Debated hotly.

Pursued intermittently. And supported halfheartedly in response to various short-lived crises. Until now.

Today, the need to move beyond the status quo is driven not by "doom-and-gloom" predictions but by realities on the ground. The global economy is under constant threat as a result of rising energy prices. Changing weather patterns linked to climate change are contributing to natural disasters that are wreaking havoc in communities from North and South America to the Middle East and Asia.

The events of the past few years show us that the transition from heavy reliance on fossil fuels to greater emphasis on clean, sustainable energy sources cannot wait. To defend against the devastating economic impact of inevitable oil price spikes and the environmental threats associated with global warming, we must act now. In many ways, islands are on the front lines of this battle.

\section{Islands: Leading the Transition to a Clean Energy Future}

Islands are extremely dependent on fossil fuels, and because of their geographic isolation, they tend to have very high retail electricity rates. Islands are also especially vulnerable to the impacts of climate change.

On the other hand, islands typically have abundant renewable resources, small populations, and the political will to change, making them ideal places to showcase the technical and economic viability of renewable energy. 


\section{EDIN-USVI}

Energy Development in Island Nations (EDIN) is an international partnership focused on addressing the unique energy challenges islands face. EDIN aims to help island nations and territories increase their energy security by adopting energy efficiency measures and harnessing their indigenous renewable resources.

Through initiatives such as the U.S. Virgin Islands (USVI) pilot project launched in late 2009, EDIN is developing a holistic model for clean energy development that can be replicated by islands worldwide.

Like many island communities, the USVI is almost $100 \%$ dependent on imported oil for electricity and transportation. This leaves the territory vulnerable to global oil price fluctuations that can have devastating economic effects.

USVI electricity costs are nearly three times the U.S. average, making energy price spikes extremely difficult for ratepayers to absorb. And like other island communities around the world, the U.S. Virgin Islands are among the first to feel the environmental impacts associated with fossil fuel-based energy sources and carbon emissions-rising sea levels, intense hurricanes, and widespread loss of coral reefs.

Through the EDIN project, clean energy champions in the USVI are tapping in to the technical expertise of the U.S. Department of Energy's (DOE's) National Renewable Energy Laboratory (NREL), as well as financial and technical support from DOE and the U.S. Department of the Interior (DOI), to help the territory reduce its reliance on fossil fuels and transition to a clean energy future. EDIN-USVI is a collaborative effort among many public and private groups, led by the $\mathrm{VI}$ Water and Power Authority (WAPA), the VI Energy Office (VIEO), DOE, DOI, and NREL.

While the USVI doesn't have the size to impact global markets or bend the curve of global warming, it does have a unique opportunity to strengthen its economy, protect its environment, and demonstrate to the world that energy transformation is possible.

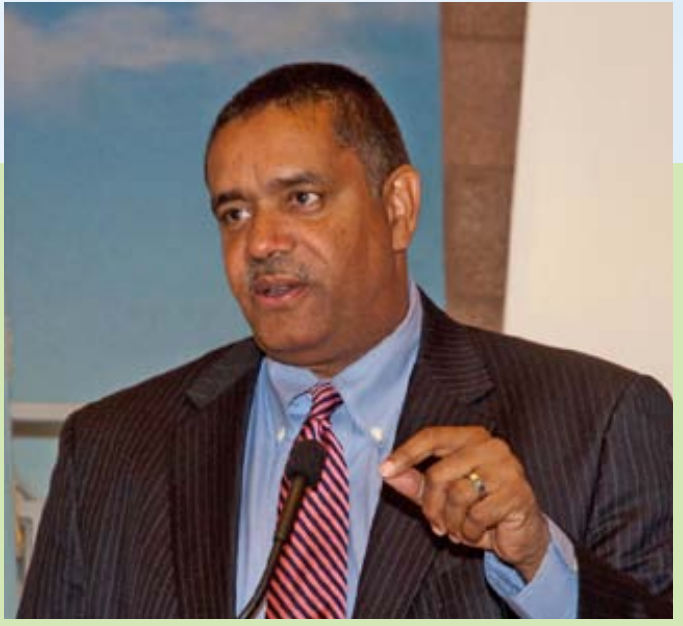

USVI Gov. John P. de Jongh Jr. at the inaugural EDINUSVI workshop, held at NREL in Golden, Colorado, February 2010. Photo by Rebecca Ottaway, NREL/PIX 19597

\section{$60 \%$ by 2025}

"We must-together-embrace the challenge of transforming our community and the underpinnings of our economy to build the future that we need and must reach, not just for ourselves, but, more importantly, for our children. ... .

\section{"The high cost of energy is a major} concern for the individual ratepayer, and a key issue in our economic development. As a territory, we are implementing our plan to reduce our dependence on fossil fuels by $60 \%$ over the next 15 years."

-Gov. John P. de Jongh Jr. State of the Territory Address, January 24, 2011

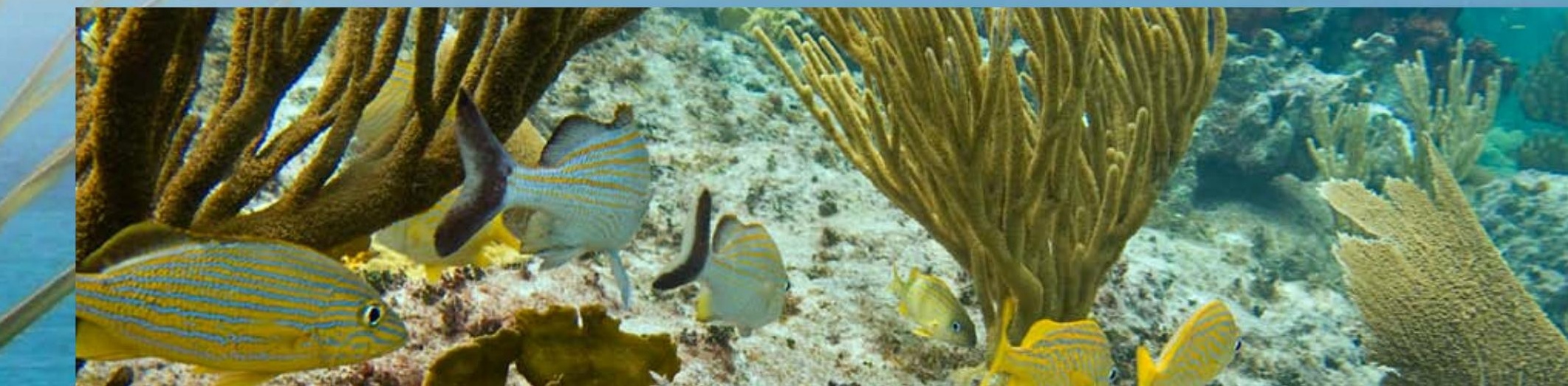


EDIN-USVI is a long-term investment in a more secure, sustainable energy future. It represents a sustained, collaborative effort to:

- Minimize the territory's dependence on fossil fuels

- Enhance energy affordability and reliability

- Reduce environmental threats associated with global warming

- Build a thriving clean energy sector that generates local green jobs

- Preserve the natural resources that are the lifeblood of the islands

- Lead the way toward a clean energy future for the USVI and the Caribbean.

Through energy efficiency and renewable energy technology development, the EDIN-USVI project aims to lead the transition to a clean energy economy and advance the USVI's goal of reducing fossil fuel-based energy consumption $60 \%$ from business as usual by 2025 .

There is no silver bullet. To realize Governor de Jongh's vision of fundamentally changing the way the territory uses energy, the USVI will need to deploy a variety of clean energy technologies. Through EDIN, clean energy advocates in the USVI have developed a comprehensive plan for addressing the territory's energy challenges-a road map to a clean energy future.

\section{EDIN-USVI Working Groups}

People are the foundation of any community energy transformation. Beginning in June 2010, EDIN-USVI formed working groups comprising many public and private stakeholders, including representatives of the utility, territorial and federal government agencies, businesses, schools, nonprofits, and concerned citizens.

Building on the governor's vision, the working groups set out to identify and implement the specific tactics that would enable the USVI to achieve its $60 \%$-by-2025 goal. Working collaboratively, these groups have adopted an integrated deployment strategy that incorporates a broad range of energy efficiency measures and renewable energy technologies into a comprehensive solution that addresses the territory's energy needs.
EDIN-USVI Chair

Gov. John P. de Jongh

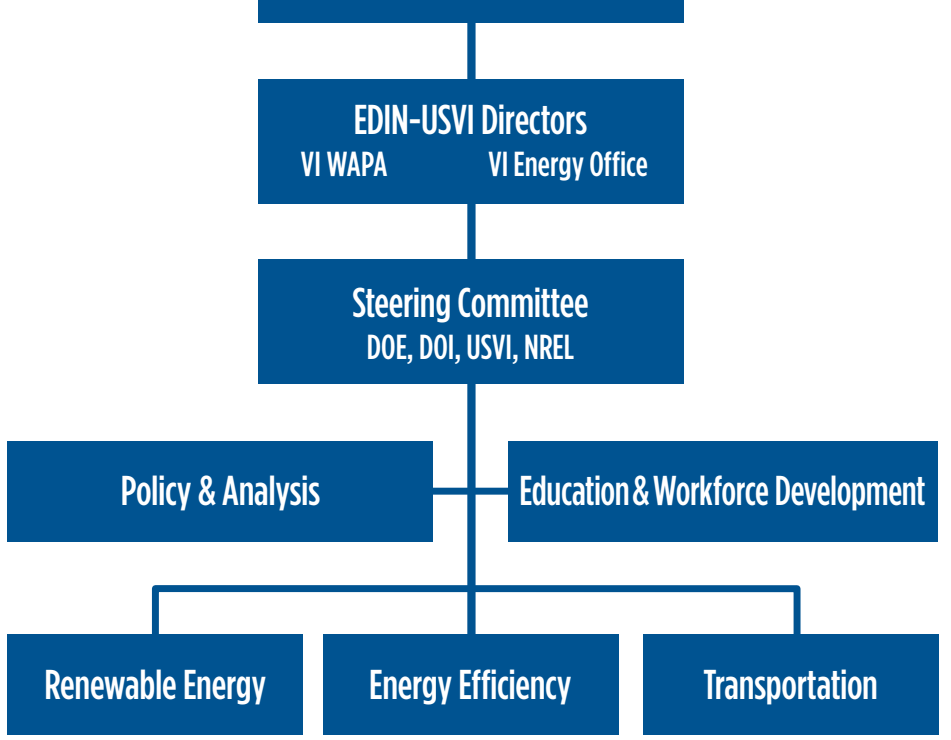

The EDIN-USVI project is a collaborative effort. IIIustration by NREL

Over the past year, the EDIN-USVI working groups have been focused on five key areas:

1) Energy efficiency

2) Renewable energy

3) Transportation

4) Education and workforce development

5) Policy and analysis

In partnership with DOE, DOI, NREL, WAPA, and VIEO, these five groups are charting the course for energy transformation in the USVI and the Caribbean region.

\section{Energy Efficiency Working Group}

The Energy Efficiency working group is focused on the many energy efficiency opportunities in the USVI. Its work is aimed at enabling businesses and individuals to realize significant cost savings by making simple changes that reduce energy use and by investing in more efficient lighting, air-conditioning, and appliances. 


\section{Renewable Energy Working Group}

The Renewable Energy working group is focused on the costeffective deployment of renewable energy in the territory. The USVI has an abundance of potential renewable energy resources, including solar, wind, waste-to-energy (WTE), and biomass. The Renewable Energy group is working on several fronts to help identify the best mix of renewable energy on the islands.

\section{Transportation Working Group}

The Transportation working group's focus is on creating a sustainable transportation system for USVI residents and tourists. Among the first steps for this group are developing a baseline measurement of the current fuel use for transportation and creating a plan to transform fuel use in the future.

\section{Education and Workforce Development Working Group}

Forging a clean energy future will require a shift in consciousness that builds grassroots support for the territory's clean energy goals and brings about changes in the way people, institutions, and businesses use and think about energy. The Education and Workforce Development working group is focused on identifying and developing the tools and programs essential to this transformation.

\section{Policy and Analysis Working Group}

Governmental policy is foundational to reshaping the regulatory landscape to clear the way for an energy transformation. The Policy and Analysis working group is focused on assisting USVI lawmakers and other clean energy advocates in this critical area.

\section{The Energy Planning Process}

Working with a broad set of stakeholders in the planning phase, the EDIN-USVI working groups began by developing a set of task-related initiatives to be considered. Next, they performed detailed analyses to identify the mix of energy efficiency and renewable energy that would enable the USVI to achieve its $60 \%$-by-2025 goal. They used the data gathered during the assessment phase to develop the USVI Energy Road Map.

The implementation phase is ongoing, and while there is a great deal of work yet to be done, the working groups have already achieved some notable early wins that have helped build grassroots support for the EDIN-USVI plan and projects.

\section{A Model for Energy Planning}

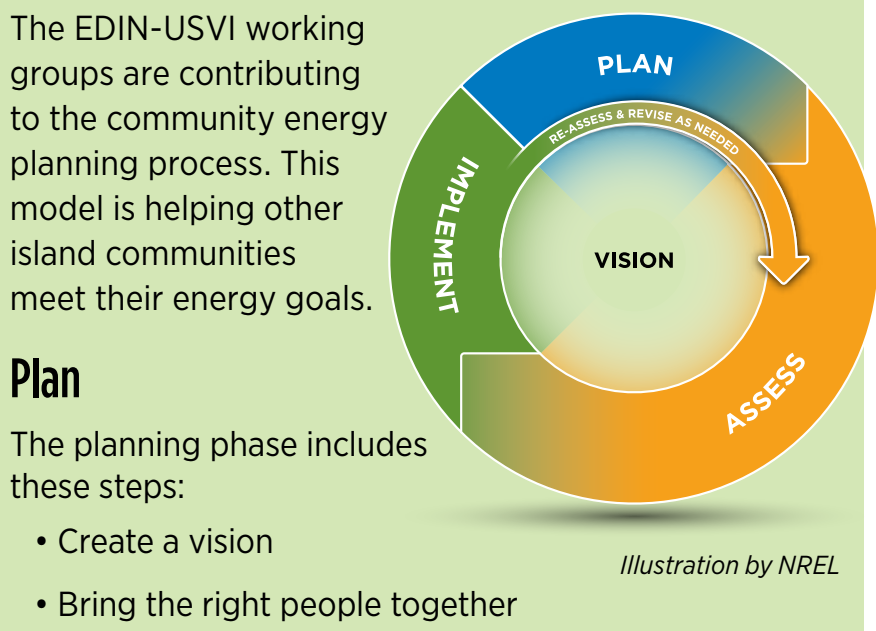

The goal of this phase is to create a vision for the community's energy transformation.

\section{Assess}

The assessment phase includes these steps:

- Determine an energy baseline

- Evaluate options

- Develop goals

- Prepare a plan

- Get feedback on the plan from a broad set of stakeholders

The goals of this phase are to:

- Determine the community's energy baseline

- Establish specific, measurable, attainable, relevant, and time-bound goals for energy transformation

- Put the goals into a plan for action.

\section{Implement}

The implementation phase includes these steps:

- Develop, finance, and implement projects

- Create early successes

- Evaluate effectiveness and revise as needed

The goals of this phase are to:

- Implement energy projects that can build community support for ongoing and future energy projects

- Measure the progress and effectiveness of the plan and its projects. 


\section{The Goal: Reduce Fossil Fuel Use 60\% by 2025}

In 2010, WAPA burned 2.6 million barrels of oil to generate 900 million kilowatt hours (kWh) of electricity and 270,000 barrels of oil to desalinate nearly 2 billion gallons of drinking water. If no action is taken to improve the situation, oil use for electricity and water production in the USVI is predicted to grow at a rate of $1.2 \%$ annually and reach 3 million barrels by 2025. This is the business-as-usual (BAU) case.

\section{Energy Efficiency Goal}

More than half of the $60 \%$-by-2025 goal can be achieved through a combination of more efficient water treatment and electricity generation and increased end-use efficiency. This will require doubling generation efficiency while cutting building energy use by at least a quarter. These efforts will reduce oil use by 1.1 million barrels per year by 2025 .

Achieving the energy efficiency goal will also require reducing the USVI's reliance on petroleum for transportation. The Transportation working group is compiling the USVI 2025 Transportation Reduction Plan, which will be factored in to the energy efficiency goal down the road.
Business as usual vs. $60 \%$ by 2025 . Illustration by NREL

Achieving the 60\%-by-2025 goal will require deploying an aggressive mix of energy efficiency and renewable energy technologies, and various mixes were considered in the development of the Road Map. The working groups deemed the scenario illustrated below to be most likely; however, others are possible. The EDIN-USVI team intends to monitor progress and update the Road Map every two years.

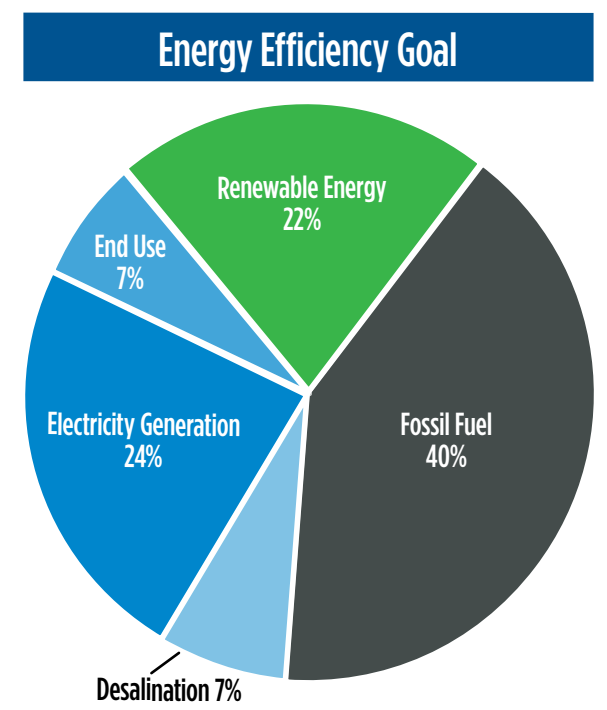

Achieving the USVI's energy efficiency goal will require improvements in end-use efficiency, water treatment methods, and electricity generation and distribution. Illustration by NREL

\section{Cost Effectiveness of Energy Efficiency}

The graph on the following page illustrates why energy efficiency is such an important part of the $60 \%$-by-2025 goal. The height of the bar represents the cost effectiveness of the tactic in barrels of oil equivalent reduced per year per million dollars spent $(\mathrm{BOE} / \mathrm{yr} / \$ \mathrm{M})$. The width is proportional to the impact of the tactic as measured in BOE/yr. So the wider the bar, the greater the impact, and the taller the bar the more cost effective. Note that while end-use efficiency only represents $7 \%$ of the overall goal, tactics for increasing government, residential, and commercial energy efficiency are the most cost effective. End-use efficiency is the low-hanging fruit.

\section{End-Use Energy Efficiency}

The total amount of energy used by buildings in the USVI can be reduced significantly with off-the-shelf solutions. Achieving the end-use efficiency goal will require one in four households and businesses to adopt energy efficiency measures that reduce their energy use anywhere from 15\% to 35\% by 2025 . In addition, the Road Map assumes three in four government buildings will reduce energy use, as mandated by Act 7075, the Virgin Islands Renewable and Alternative Energy Act of 2009.

By achieving these projected levels of participation, the USVI can reduce fossil fuel use by 78 million $\mathrm{kWh}$ annually by 2025 -the equivalent of 200,000 barrels of oil per year. 


\section{Impact and Cost Effectiveness of Energy Efficiency Tactics}

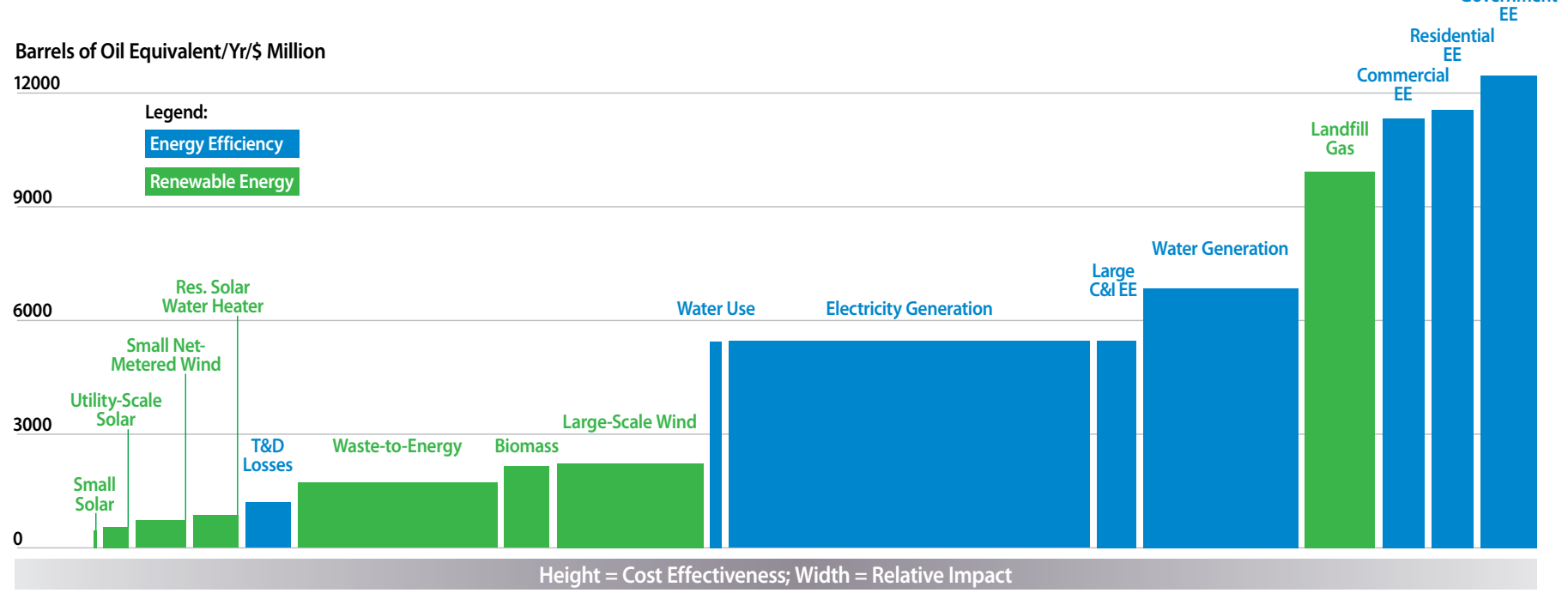

This graph illustrates the cost effectiveness and impact of the various energy efficiency and renewable energy tactics considered by the Road Map. The height of each bar represents cost effectiveness, or bang for the buck. The width represents energy savings assumed in the analysis. All scenarios are aggressive. Illustration by NREL

\section{Residential Energy Efficiency}

Based on home audits and building simulations, the Energy Efficiency working group performed detailed energy modeling for different types of homes in the territory. The figures below illustrate a 3,000-square-foot home and a typical 900-square-foot home in the USVI. The modeling performed on each type of home indicated that energy efficiency measures can effect a $25 \%$ reduction in residential energy use.

Efficient air-conditioning, shading, day lighting, and cool roofs are all examples of such measures. Cool roofs, for instance, are insulated so as to maintain a lower temperature than traditional roofs while the sun is shining, typically through reflectance technologies. Painting the roof white is a common tactic, but not all cool roofs need to be white. Special coatings allow roofs of any color to reduce the amount of heat they absorb. In the USVI, for example, the beautiful red roofs of Charlotte Amalie and Christiansted could be replaced with cool roofs without losing their distinctive color.

\section{Government and Business Energy Efficiency}

Preliminary energy audits suggest there are opportunities to significantly reduce energy use in governmental and commercial buildings. By addressing inefficient and excessive lighting and inefficient air-conditioning systems, these buildings could cut electricity use by $15 \%$ to $25 \%$.

Of course, such measures require up-front capital investment, and this may strain the budgets of USVI businesses

\section{Building Modeling}
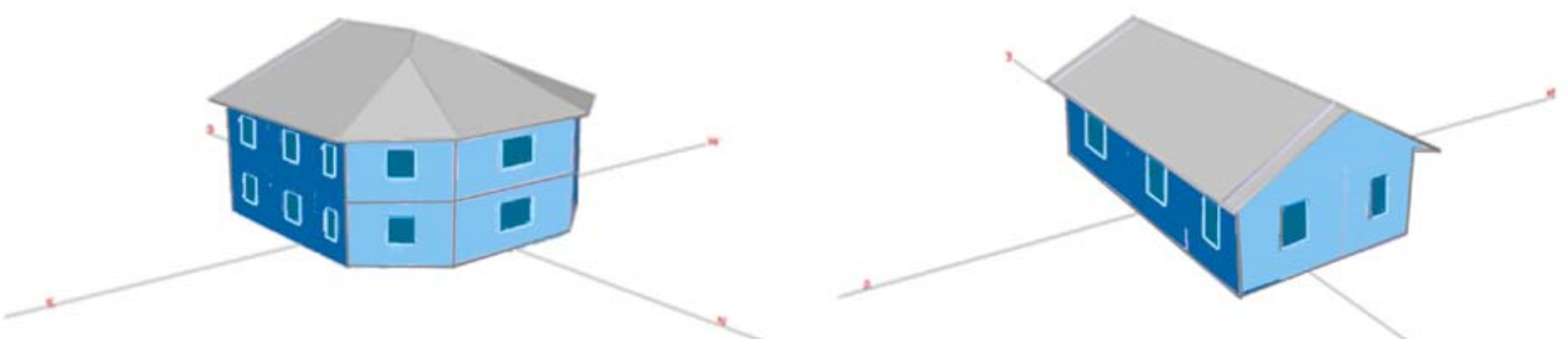

Computer modeling was performed on two types of homes in the USVI: a 3,000-square-foot home with air-conditioning and a 900-square-foot home (with and without air-conditioning). For more information, visit edinenergy.org/usvi.html. Illustration by NREL 


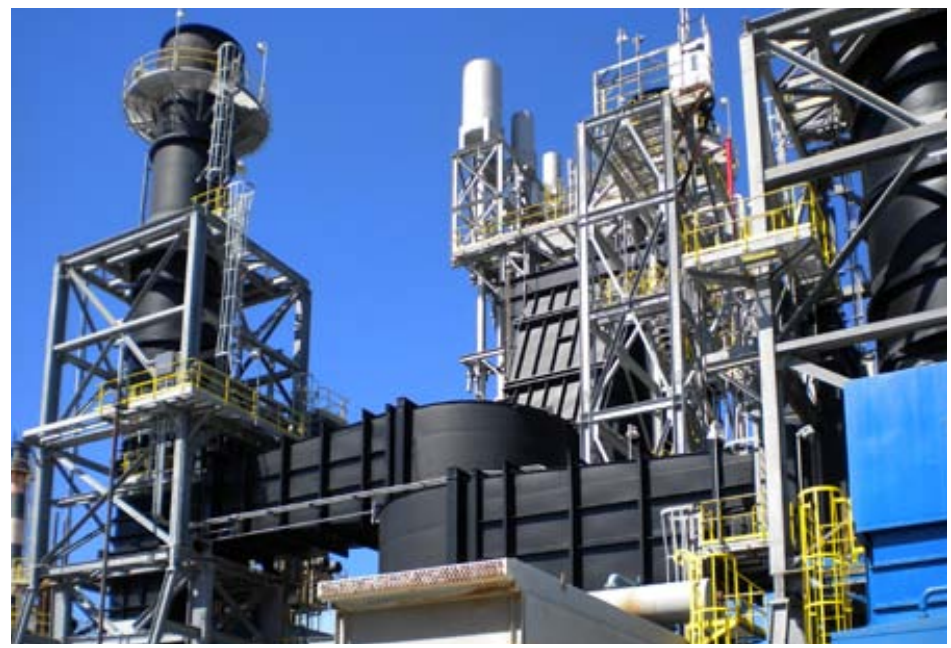

WAPA plant on St. Croix. Photo by Dan Olis, NREL/PIX 18598

and government agencies, many of which are already under considerable financial pressure.

The USVI is exploring the use of energy savings performance contracts (ESPCs) offered by energy service companies (ESCOs). In an ESPC, a third party pays the up-front cost of the building improvement and then recoups the cost over time from the building owner by sharing in the savings realized through lower energy bills.

\section{Generation Efficiency}

The overall goal for generation efficiency is to reduce the amount of oil used to generate water and electricity by 920,000 barrels of oil per year by 2025. Increasing the efficiency of generation and distribution will require WAPA to switch from distillation to reverse osmosis for water treatment and to install heat recovery steam generators (HRSGs) at its plants on St. Thomas and St. Croix.

\section{Reverse Osmosis}

WAPA generates drinking water by cleaning and removing salt from seawater. The majority of desalinated water in the USVI today is generated using multi-effect distillation (MED), a process that uses heat and vacuum to boil the water, leaving the salt behind. A far more efficient technology, developed since the utility installed its MED systems decades ago, is reverse osmosis (RO). RO uses specially designed filters to remove salt and other contaminants while using up to $75 \%$ less energy.

\section{Heat Recovery Steam Generators}

The efficiency of WAPA's power generation can also be improved dramatically by installing HRSGs that capture the heat that escapes "up the stack" and use it to generate steam. This steam can be used to spin turbines and generate electricity. The recently installed HRSG at WAPA's St. Croix plant (pictured at left) adds 19 megawatts (MW) of power without using a single drop of additional oil.

Using waste heat to make steam has allowed WAPA to idle diesel boilers, saving about 1,750 gallons of diesel fuel per hour when the plant is running at full load.

\section{Energy Efficiency Accomplishments to Date}

- Initiated building energy efficiency work at 11 schools

- Installed high-efficiency LED street lights on St. John

- Developed building efficiency educational materials

- Installed a reverse osmosis system at the St. Croix WAPA plant to generate half of desalinated water

- Installed HRSG at the St. Croix WAPA plant, adding 19 MW of power without burning more oil

\section{Renewable Energy Goal}

Achieving the USVI's renewable energy goal will require deploying a mix of commercially available technologies. By increasing renewable energy development, the USVI aims to reduce oil consumption by 660,000 barrels per year by 2025 .

Through careful analysis and modeling using the Hybrid Optimization Modeling Tool (HOMER), the Renewable Energy working group is working to identify the most cost-effective combination of technologies for attaining that goal.

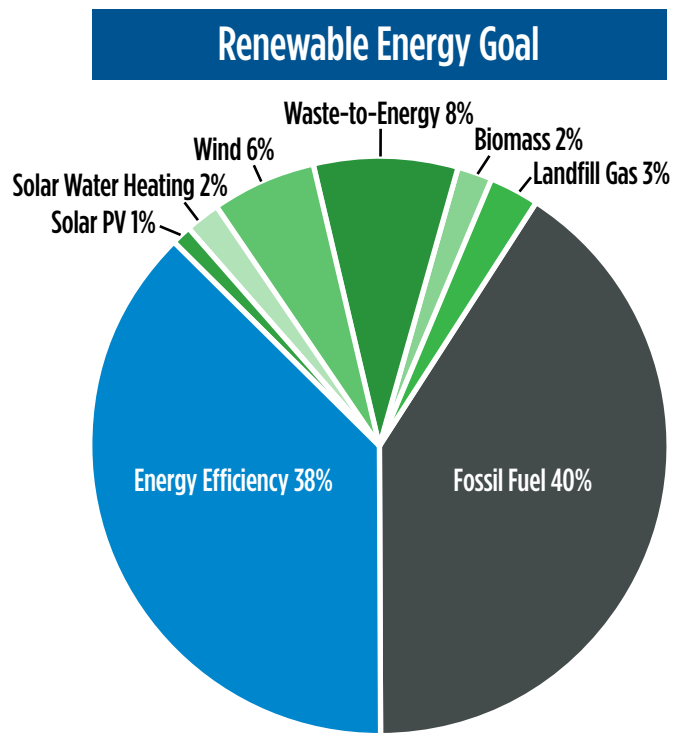

This mix of renewable energy technologies meets the USVI renewable portfolio standard (RPS) established by Act 7075 . Illustration by NREL 
The HOMER analyses performed to date have been focused on helping WAPA determine the economic feasibility of installing a mixture of renewable energy in the USVI, including $5 \mathrm{MW}$ of solar photovoltaic (PV) energy and $15 \mathrm{MW}$ of wind energy on St. Thomas and St. Croix.

The analyses indicated that while PV is not cost effective at the current installed cost of $\$ 7.50$ per watt without subsidies or customer contributions, it will be once the installed cost drops below $\$ 5.50$ per watt or fuel prices increase from $\$ 0.44$ per liter ( $\$ 1.70 /$ gallon) to $\$ 0.60$ per liter ( $\$ 2.30 /$ gallon).

On the other hand, the analyses revealed that wind energy is cost effective even at the present fuel cost of $\$ 0.44 /$ liter ( $\$ 1.70 /$ gallon) and at modest wind speeds as low as 5 meters per second. Furthermore, installing just $15 \mathrm{MW}$ of wind could reduce the consumption of diesel fuel for power generation by as much as $9 \%$ on St. Thomas and 14\% on St. Croix.

Though wind power is presently more cost effective than PV, diversifying energy sources is important for enhancing energy reliability in the territory. PV often complements wind power, since the solar resource is available during the day, and the wind resource is generally higher at night.

Note that the EDIN-USVI Road Map excludes technologies that have yet to be commercially deployed in the United States, such as ocean thermal energy conversion (OTEC), offshore wind, and marine and hydrokinetic (MHK) energy. It also excludes natural gas, "clean" coal, and nuclear energy from the mix.

\section{Cost Effectiveness of Renewable Energy}

The most cost-effective mix of renewable energy and diesel depends on many variables, including the cost of the renewable technologies, the quality of the renewable energy resource, and the cost of diesel. For each of these variables, an optimal lowest-cost generation mix can be determined using simulation tools such as HOMER.

The HOMER software uses local solar and wind resource data and component data to simulate hour-by-hour operation of renewable energy systems and load profiles to rank the economic viability of various system configurations according to net present cost. The HOMER analyses performed to date indicated that wind and solar PV are economically sound alternatives to diesel in the USVI, given today's high oil prices.

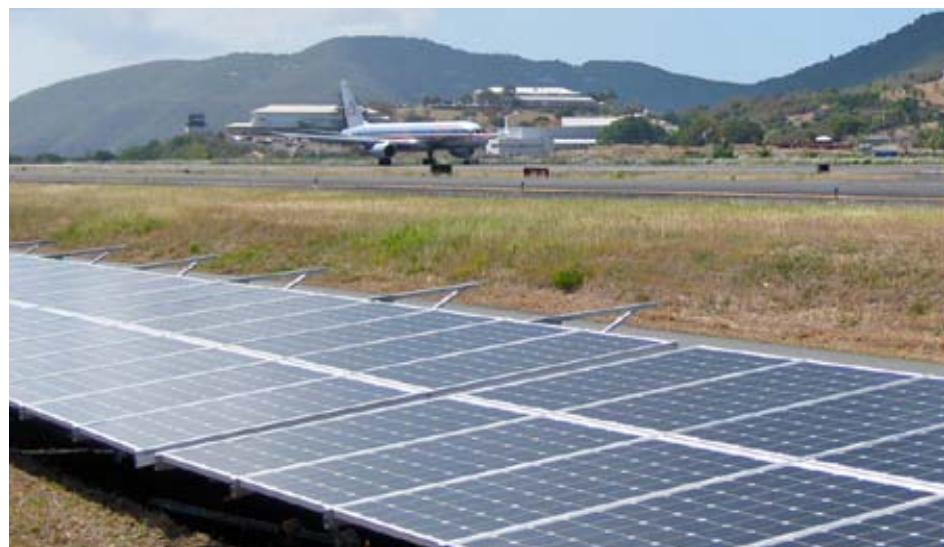

A 448-kW PV system installed at the Cyril E. King Airport on St. Thomas in April 2011. Photo by Adam Warren, NREL/PIX 18953

\section{Solar}

The overall goal for the solar sector is to deploy $9 \mathrm{MW}$ of solar PV and to install solar water heating (SWH) in $40 \%$ of USVI homes. This will reduce fossil fuel use by the equivalent of 160,000 barrels of oil per year by 2025 .

\section{Solar PV}

As indicated by the maps below, the UVSI has excellent solar resource for PV energy generation. The net-metering laws specified in Act 7075 provide individuals and businesses with an opportunity to take advantage of this source of clean, renewable energy. Homeowners can install up to $20 \mathrm{~kW}$ each, businesses $100 \mathrm{~kW}$, and government buildings $500 \mathrm{~kW}$. For its part, WAPA released a request for proposals in May 2011 to install 10 MW of solar PV by December 2013.

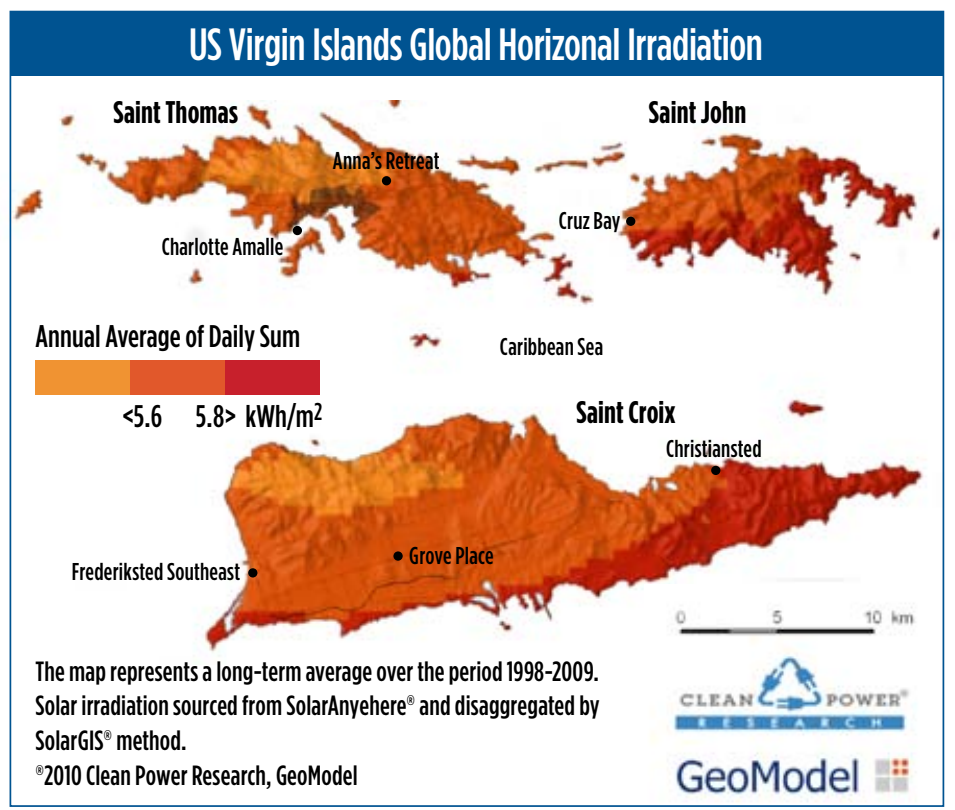

USVI solar resource map. Illustration from Clean Power Research 


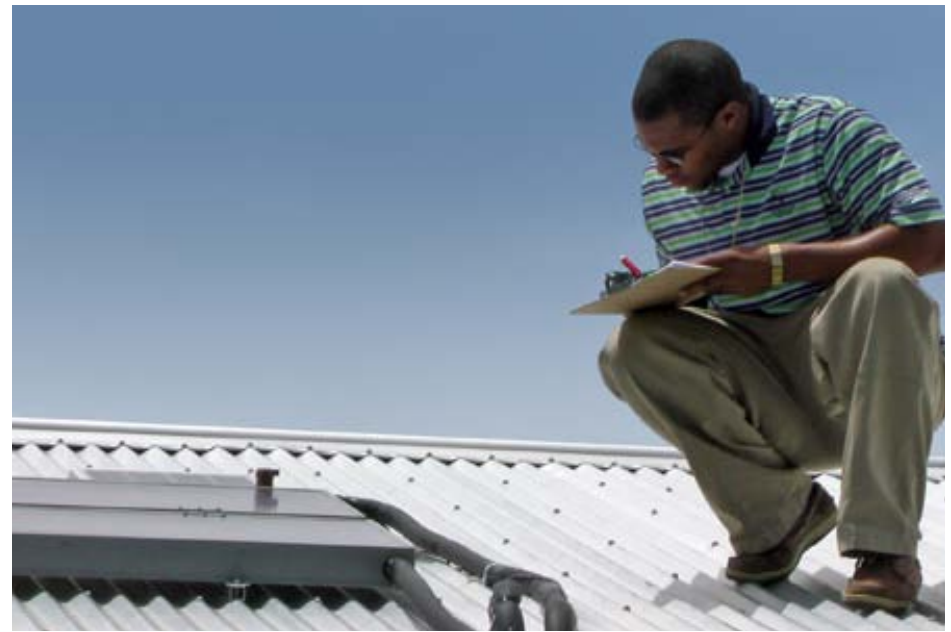

An Energy Office intern inspecting a solar collector. Photo from Don Buchanan, Virgin Islands Energy Office

\section{Solar Water Heating}

The same sun that can be used to generate electricity is more than adequate to heat the water in USVI homes, businesses, and institutions.

Act 7075 positions the government to lead by requiring that SWH be installed in government buildings where it is determined to be cost effective. In addition, for new construction throughout the territory, including "all new and substantially modified developments," the law requires developers to install energy efficient SWH systems. The EDIN-USVI Road Map assumes that $40 \%$ of USVI households will take advantage of existing SWH incentives, which would reduce oil use by 61,000 barrels per year by 2025.

Analyses performed by the Renewable Energy working group revealed that when incentives such as low-interest loans, rebates, and tax credits are factored in, SWH can yield a solid return on investment. A solar water heater can save a family of four an estimated $\$ 250$ per year initially, and annual savings should double once the 5 -year loan is paid off.

\section{Solar Accomplishments to Date}

\section{- Updated solar resource maps for the USVI}

- Implemented SWH rebate and loan program

- Received loan applications for 450 SWH systems (April 2010-April 2011)

- Implemented net-metering program mandated by Act 7075

- Installed 176 kW of small PV systems

- Installed 448-kW solar PV system-the largest in the region-at Cyril E. King Airport

\section{Wind}

There is significant potential for wind to provide a lower-cost, cleaner source of energy for the USVI. The overall goal for the wind sector is to install $22.5 \mathrm{MW}$, producing 67.5 million $\mathrm{kWh}$ annually by 2025-the equivalent of 178,000 barrels of oil per year. This will be accomplished by deploying a mix of small and utility-scale wind.

Initial wind studies show that there is access to the trade winds along the east-facing coastlines and along prominent ridges of St. Thomas, St. John, and St. Croix. The maps below indicate where the potential for wind is the greatest.

Unfortunately, these maps do not provide the detailed data that is required by banks that loan money for the installation of utility-scale wind turbines. To gather this "bankable" data, the

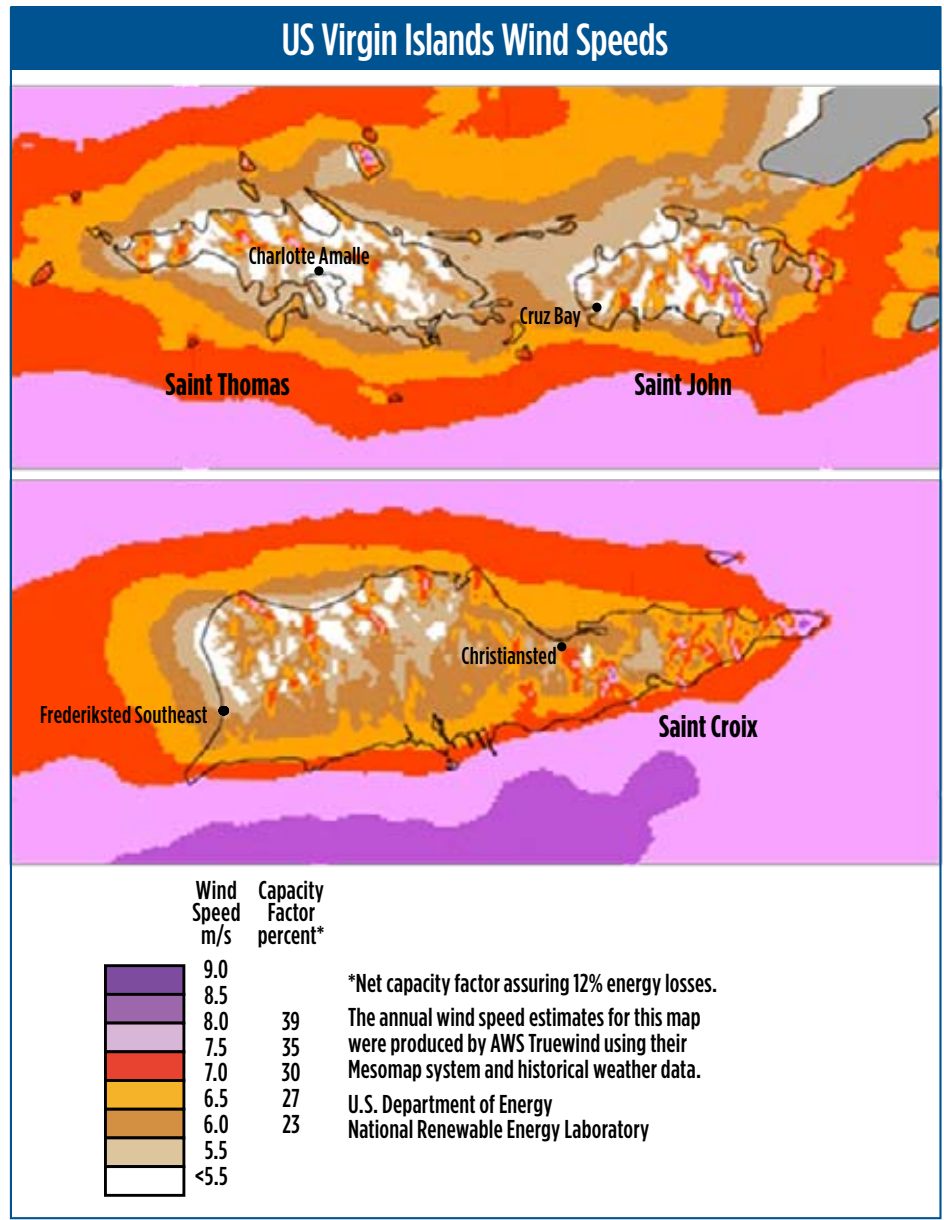

Annual wind speed estimates for the U.S. Virgin Islands. Illustration by NREL 


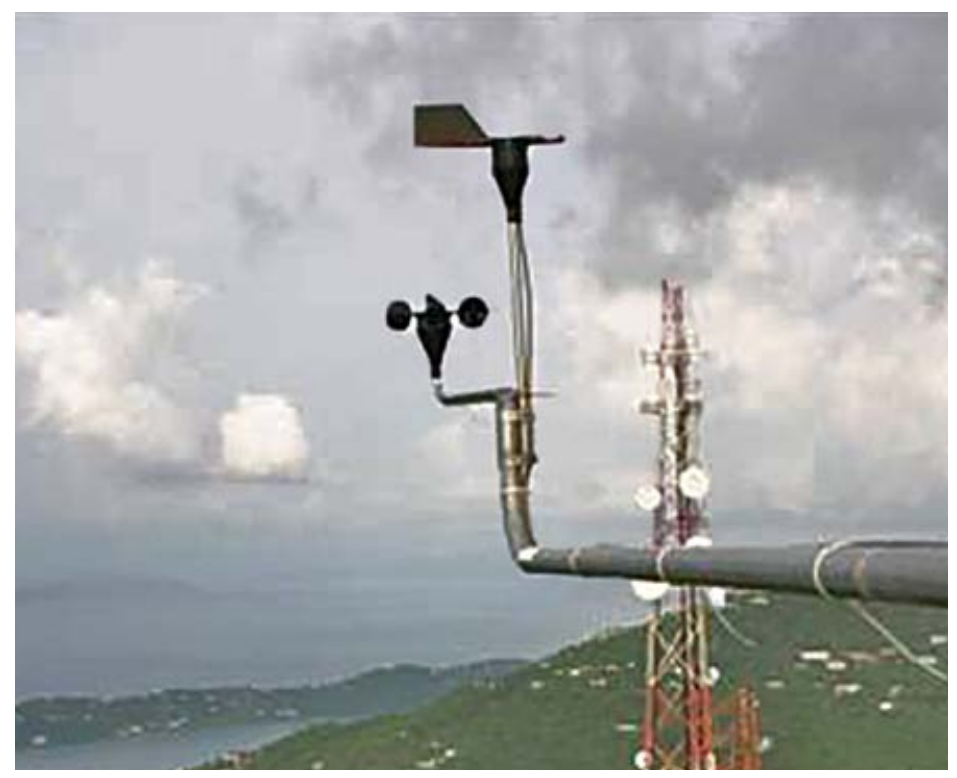

A wind anemometer used to gather data that informed the Renewable Energy working group's assessment of the wind resource on St. Thomas. Photo from the Virgin Islands Energy Office

Renewable Energy working group has been laying the groundwork to install anemometers, such as the one pictured above, at the most promising wind sites that have been identified on St. Thomas and St. Croix.

The anemometers, which will be fixed at various heights on 60-meter towers, will measure wind speed and direction, along with a variety of other weather data. (In the USVI, these tower locations will also be instrumented with solar measurement devices that will help the EDIN team understand how variability in sunshine will affect the existing grid system [see graph on page 11]). Collectively, this data can be used to estimate the annual output of wind turbines installed in the locations of the anemometers and to update the wind maps for the entire territory.

\section{Wind Accomplishments to Date}

- Developed low-resolution wind maps

- Identified sites with high potential for utility-scale wind

- Signed contracts to install wind anemometers and sonic detection and ranging (SODAR) systems in the USVI

\section{Biomass, Landfill Gas, and Waste-to-Energy}

Biomass, landfill gas, and waste-to-energy (WTE)-all plentiful in the USVI-are excellent renewable sources of dispatchable energy. The overall goal for the WTE sector is to install 16.5 MW, producing 21 million kWh annually by 2025 -the equivalent of 380,000 barrels of oil per year.

\section{Biomass Energy}

Initial studies indicate that there is potential for a small-scale biomass power system in the USVI. Work with the St. Croix Environmental Association indicates that anywhere from $3 \mathrm{MW}$ to $5 \mathrm{MW}$ of power can potentially be generated from harvesting biomass crops and nuisance plants such as the tan-tan tree (Leucaena glauca), also known as wild tamarind.

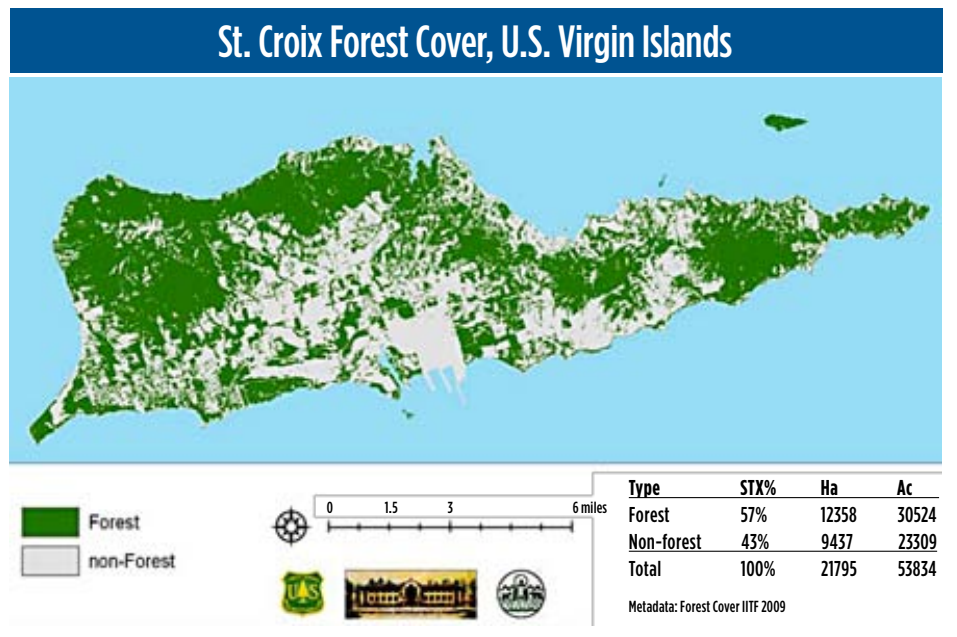

Biocrop potential map for St. Croix. Illustration from U.S. Virgin Islands Forest Resources Assessment and Strategies, June 2010, Marilyn Chakroff, Forestry Division, VI Department of Agriculture, Kingshill, VI.

\section{Landfill Gas}

Both of the major landfills in the USVI-Bovoni on St. Thomas and Anguilla on St. Croix-are under U.S. Environmental Protection Agency (EPA) orders to close. While this poses serious challenges with regard to the handling of new waste, it also provides an opportunity to cap the landfills and harvest the resulting landfill gas for energy generation.

The EPA's Landfill Methane Outreach Program (LMOP) estimates that there is the potential for generating $3 \mathrm{MW}$ to $5 \mathrm{MW}$ of power from the existing landfills, which would dramatically reduce their greenhouse gas emissions while providing a renewable source of energy. 


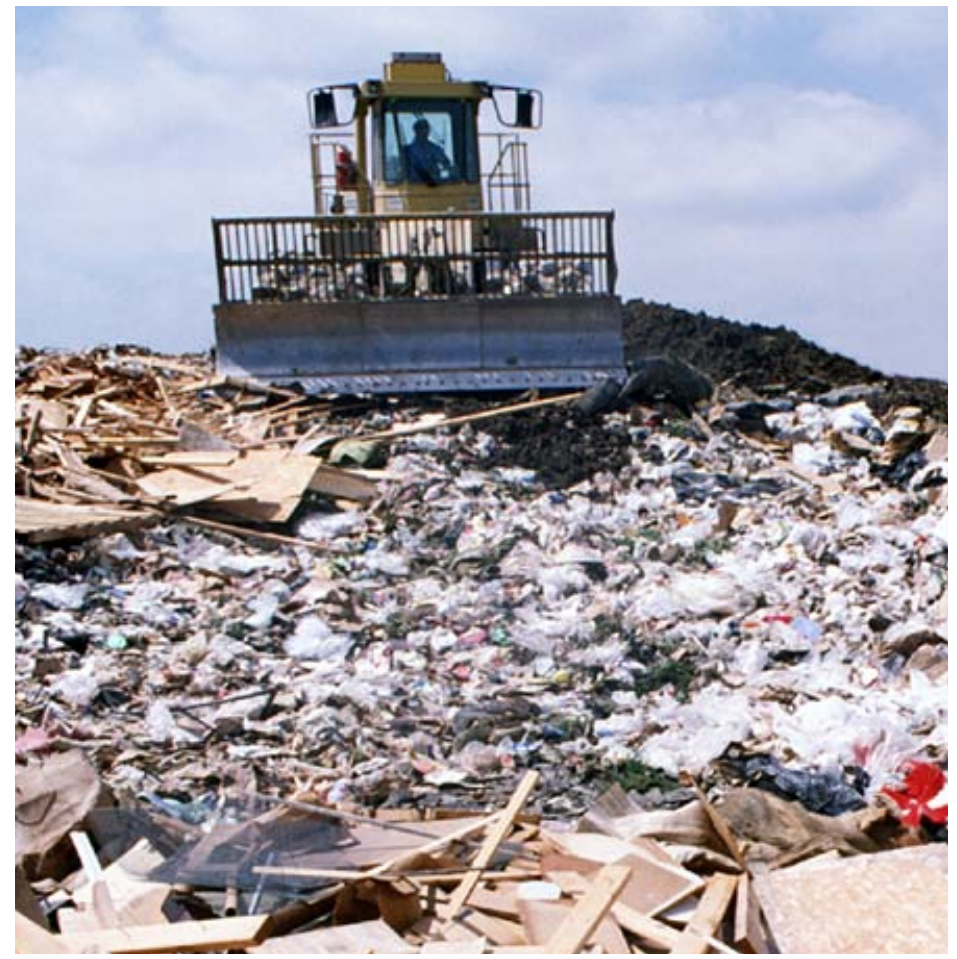

Waste-to-energy offers a solution to two looming challenges the USVI faces: waste management and energy security. Photo by David Parsons, NREL/PIX 05289

\section{Waste-to-Energy}

Waste-to-energy provides another potential solution to the territory's energy and waste disposal challenges. The proposed WTE plant on St. Croix will meet $20 \%$ of the island's energy needs while contributing $37 \%$ of the overall renewable energy goal. Of course, this facility must be designed and operated in an environmentally responsible manner if it is to be a viable contributor to the USVI Energy Road Map. Fortunately, the operation of existing WTE systems suggests this is possible. Studies conducted at Columbia University demonstrate that properly designed WTE plants can meet and exceed EPA and European Union standards.

\section{Biomass, Landfill Gas, and WTE Accomplishments to Date}

- Signed power purchase agreement for 16.5 MW of WTE

- Identified potential for 3 MW-5 MW of energy generated from landfill gas

- Developed biomass crop-potential maps

- Completed biomass chemical and BTU analysis

\section{Energy Transformation Challenges}

Achieving the $60 \%$-by-2025 goal won't be easy. Each of the USVI's energy efficiency and renewable energy goals presents a unique set of challenges, and there are a variety of technical, policy, financial, and cultural hurdles that must be overcome if USVI is to succeed.

\section{Technical}

Among the technical challenges of energy transformation are grid integration, land constraints, and wildlife impacts.

\section{Grid Integration}

In general, there are two types of renewable energy sources: dispatchable and intermittent. Dispatchable sources of energy are those the utility can ramp up and scale down to meet the required demand. Landfill gas, WTE, and biomass are examples. Diesel, coal, and natural gas are examples of nonrenewable dispatchable energy sources. Intermittent energy sources are those that the utility cannot control directly. WAPA can't control when clouds block the sun or when the wind stops blowing.

The graph below shows the typical output of a solar system as clouds pass. Note the variability in power output as measured in kilowatts per minute. On a large enough scale, this variability requires the utility to maintain dispatchable sources

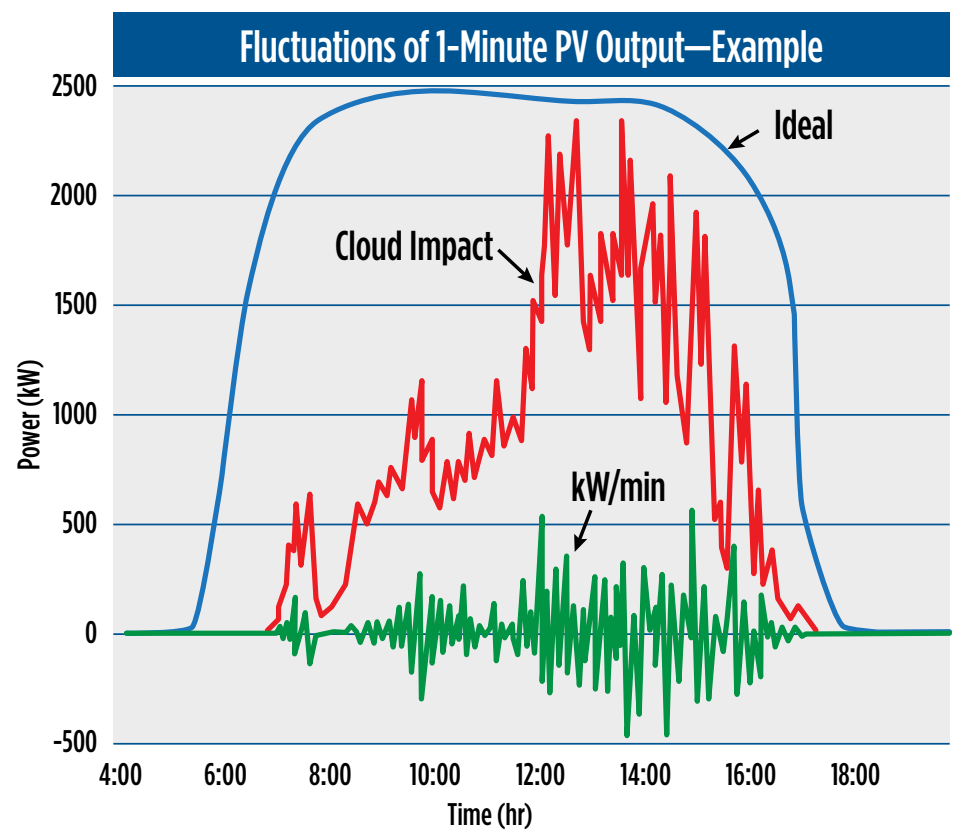

Typical output of a solar system as clouds obscure the sun. Illustration by NREL 
of energy on standby (known as spinning reserves) in case the level of renewable energy drops, since such fluctuations can reduce power quality or even shut down the grid. In order to avoid outages and maintain a reliable power supply, WAPA may need to impose limits on the amount of renewable energy that can be deployed in certain areas until it is able to update its operating practices and equipment to accommodate increased penetration of renewables.

\section{Land Constraints}

The territory's three main islands have limited land available for renewable energy projects. Solar PV requires relatively flat land or appropriately oriented roofs to be effective, and such sites are not plentiful in the USVI. Wind turbines obviously require a windy area, but the ideal wind sites in the USVI are often inappropriate due to use for housing or as nature conservatories. For this reason, much of the EDIN-USVI work to date has been focused on siting and resource assessment.

\section{Wildife Impacts}

Avian mortality is an issue that has generated opposition to wind energy development. This is a legitimate concern that must be considered along with other environmental impacts.

\section{Avian Mortality Research}

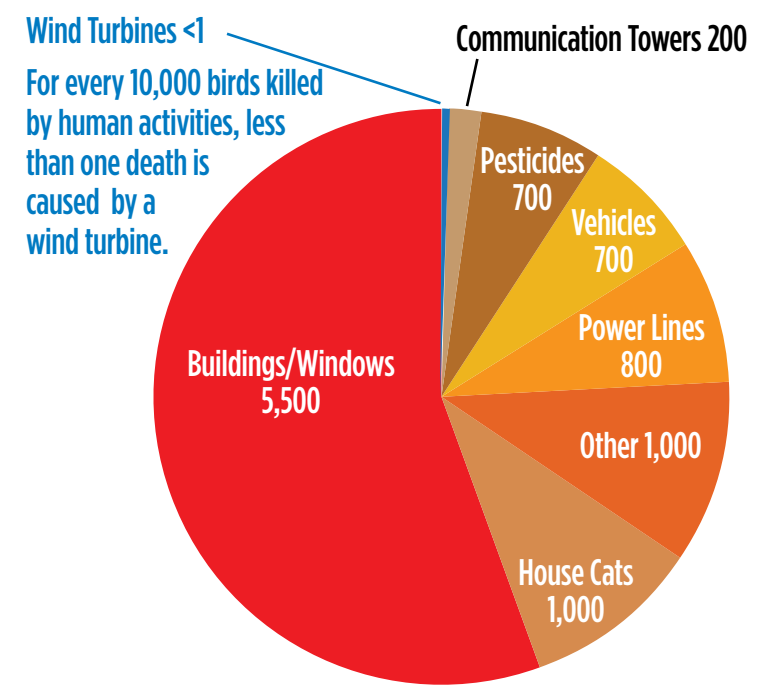

Based on data from a 2005 study conducted by the U.S. Department of Agriculture Forest Service, wind turbines account for less than $1 \%$ of bird deaths caused by human activities. Careful site selection can help minimize avian mortality. Illustration by NREL
A big-picture, view, however, also demands that the risk to birds, which studies have shown to be minimal, be weighed against the environmental benefits of wind energy. Bird and bat mortality can be managed through proper siting informed by wildlife impact studies. Compliance with stringent federal regulatory requirements designed to protect the environment, along with sensitivity to local environmental concerns, can help ensure that wildlife and other environmental impacts of wind turbines are minimal.

\section{Policy}

Among the policy challenges of renewable energy development are regulatory processes and building codes.

\section{Regulatory Processes}

A healthy renewable energy industry requires streamlined regulatory, taxation, and permitting processes. Delays in permitting and lack of clarity in interconnection processes can stifle growth and delay the creation of green jobs. A top-down assessment of policies and regulations is needed if the USVI is to realize the full potential for clean energy deployment in the territory.

\section{Building Codes}

Building codes, such as the IECC 2009 Tropical Code, are excellent means for improving the energy efficiency of USVI homes. To be effective, these codes must be well understood by the construction community, there must be a supply chain for energy efficient products and supplies, and the codes must be enforced. Each of these requirements has posed a challenge for the territory in the past.

\section{Financial}

Financial challenges that must be overcome include the high cost of renewable energy and energy efficiency project development on islands, and the initial capital investment needed to install renewable energy systems.

\section{High Project Development Costs}

One of the more vexing issues for the USVI is the higher cost of doing business on islands. There are many causes for this, and chief among them is lack of scale. Developers rely on the economics of scale to lower the cost of renewable energy projects-the larger the project, typically, the lower the price per watt. 
Scale is not always possible to achieve, so islands must focus on reducing other costs, such as excessive tariffs, or reducing project uncertainties that drive developers to increase costs as a hedge. Of course, if a set of islands pooled their demand for renewable energy projects, this could drive renewable energy project costs down even further.

\section{Up-front vs. Long-term Costs}

Wind and sun are free, but solar panels and wind turbines are not. On the other hand, diesel generators are relatively cheap up front-it is keeping the beasts fed that can get expensive. If renewable energy and energy efficiency projects are to make economic sense, decision makers must take the long view of the cost of energy. This is not always easy when funds are tight.

\section{Cultural}

Last but not least, there are cultural issues that must be addressed in order to gain the community buy-in and support that are needed for any clean energy initiative to succeed. These include aesthetic concerns and resistance to change.

\section{Aesthetic Concerns}

Opponents of wind energy development often raise concerns about wind turbines obstructing pristine views, so siting these projects requires forethought and sensitivity to the community's viewpoints.

On St. Thomas, among the most promising wind locations being considered is the Bovoni Landfill site. While beauty is always in the eye of the beholder, the illustration below shows that wind turbines installed on the existing landfill on St. Thomas could actually enhance the landscape.

On St. Croix, the wind sites with the greatest potential have the stacks of the local refinery in the background. Both locations

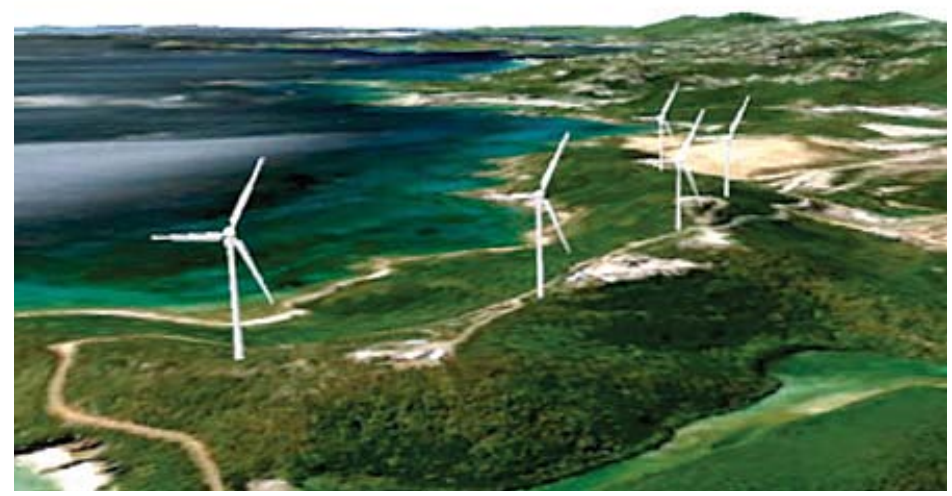

This computer-generated image is a hypothetical depiction of Bovoni Landfill on St. Thomas with more than 7.5 MW of installed wind generation. Illustration by NREL offer good potential for lower-cost, cleaner power sources for the islands without spoiling picturesque views.

\section{Resistance to Change}

Even a positive change can be difficult. Wind turbines and solar panels will change the viewscape, and energy efficiency requires attention to energy use and more informed decisions about appliance purchases and building construction. All of these changes may be met with some resistance. Energy transformation will require persistence and determination.

\section{Integrated Deployment Model}

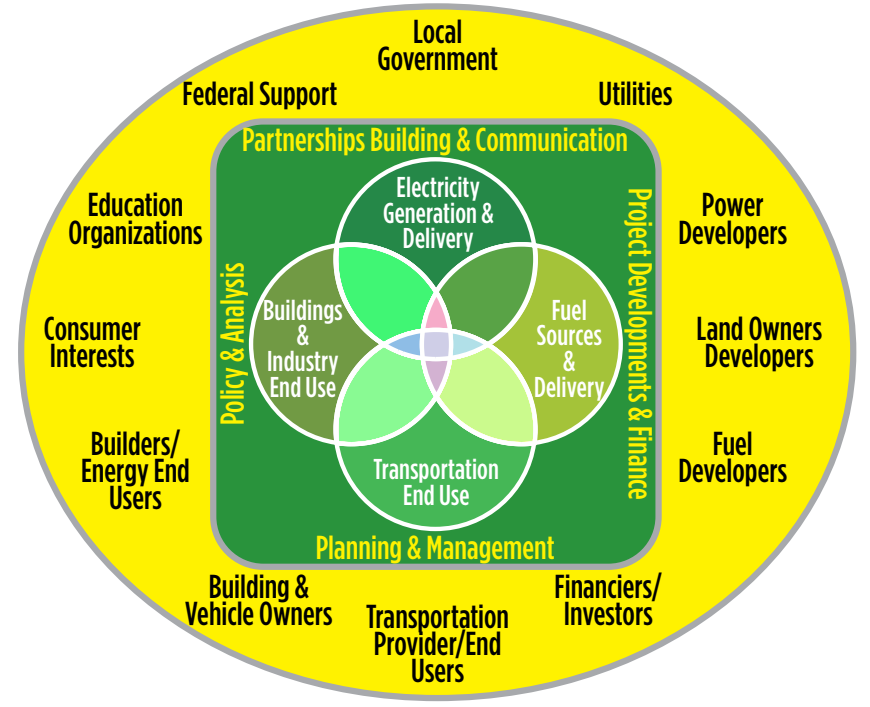

Transforming the entire energy value chain in the UVSI will require a dedicated effort focused on change through technology, policy, and deployment. Illustration by NREL

\section{Bringing It All Together}

Together, individual organizations within the territory and the EDIN-USVI partners have the knowledge and expertise to solve some of the USVI's current energy challenges. But a true energy transformation will take leaders who focus on the entire system. This requires experts focused on the application of technologies and regulations to serve as drivers; analysis to enable informed decisions; economic policies and incentives to create market pull; and stakeholder engagement to engender the political will to sustain efforts.

To succeed in forging a long-term solution to the USVI's energy challenges, many different groups will need to work together on the shared goal of reducing fossil fuel-based energy use $60 \%$ by 2025 . 


\section{Islands: Embracing}

One of the greatest hurdles to energy transformation is the instinct to "go with what we know." Consumers buy based on habit, cultural norms, and old ways of thinking. Utilities make decisions based on their existing knowledge of "tried and true" technologies. Legislators create policies based on political expedience and party-line thinking. Financiers make investments based on traditional methods of risk assessment and analysis.

To evolve beyond the status quo, consumers will need to expand their knowledge of clean energy technologies and make informed, sustainable choices. Utilities will need to open the door to new ways of doing business. Governments will need to shift their focus from politics to the public interest. Investors will need to take advantage of incentives and take a long-term view when weighing the risks and returns of energy projects.

Most importantly, people will need to understand the criticality of energy security, embrace the concept of sustainability, and actively support clean energy goals. Energy transformation involves a revolutionary shift in how entire communities think about and use energy.

Islands' inherent vulnerability to the consequences of inaction on the energy front places them in a unique position to lead by example. Each milestone they reach is an opportunity to showcase the technical and economic viability of clean energy technologies-and influence change on a global scale.

Through the EDIN project, the USVI has taken a bold step to increase its energy security and strengthen its economy. In so doing, it has also seized an opportunity to lead, charting a course for other islands to follow as they journey toward energy transformation. 
To learn more about the EDIN-USVI energy revolution and how you can be part of the solution, please visit:

edinenergy.org/usvi.html

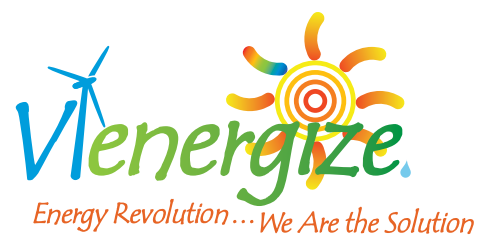

National Renewable Energy Laboratory 1617 Cole Boulevard, Golden, Colorado 80401

303-275-3000 • www.nrel.gov

NREL is a national laboratory of the U.S. Department of Energy Office of Energy Efficiency and Renewable Energy Operated by the Alliance for Sustainable Energy, LLC NREL/BR-6A42-51541 • July 2011
Photo credits: Front cover-ocean view, Karen Petersen, NREL PIX/18903; intern installing solar water heating system, Don Buchanan, VI Energy Office, NREL PIX/19339; PV panels on Montessori School roof, Don Buchanan, VI Energy Office, NREL PIX/19339; blue water, iStock 232306; wind turbines, NREL PIX/07378; palm trees, iStock 11522064; tan-tan, NREL PIX/18917; rainbow over Trunk Bay, iStock 9174728. Opening spread-ocean view, NREL PIX/18903; coral reef, iStock/16088179. Page 14-Trunk Bay, iStock 9174728.

Printed with a renewable-source ink on paper containing at least $50 \%$ wastepaper, including $10 \%$ post consumer waste. 